\title{
EL ROL DEL RUIDO EN LA CONFORMACIÓN DE LA IDENTIDAD SONORA DE UN LUGAR
}

\author{
Jaime Alejandro Cornelio Yacaman \\ Universidad del País Vasco /Euskal Herriko Unibertsitatea. Dpto. Arte y Tecnología. \\ Investigador pre-doctoral
}

\section{Resumen}

Existen elementos de identidad sonora que se encuentran en determinados ecosistemas y que responden a la complejidad de los distintos fenómenos que le rodean. El ruido es uno de los elementos más importantes puesto que forma parte de una experiencia cognoscitiva que es posible analizar e identificar. A partir de la doble pregunta de investigación: ¿cómo revelar la identidad de un lugar a través del sonido? y ¿cuáles son los elementos fundamentales de esta identidad del ecosistema que constituyen esta traducción? el objetivo del artículo es analizar el papel del ruido en la conformación de la identidad sonora territorial (ecosistemas sonoros). El análisis será realizado a partir de las teorías de la complejidad (Dewey, Morin, Whitehead) y algunos estudios de caso (obra propia, Cusack; Carruth, Polack).

\section{NOISE ROLE IN SHAPING THE SOUND IDENTITY OF A PLACE}

\section{Abstract}

There are elements of sound identity found in certain ecosystems and that respond to the complexity of the various phenomena that surround them. Noise is one of the most important elements as it forms part of a cognitive experience that is possible to analyze and identify. From the double research question: how to reveal the identity of a place through sound? and what are the key elements of this ecosystem identity that constitute this translation? the aim of the paper is to analyze the role of noise in the shaping of the sound identity of places (sound ecosystems). The analysis will be based on theories of complexity (Dewey, Morin; Whitehead) and some case studies (my personal work; Cusack, Carruth, Polack).

Keywords: NOISE; SOUND; MUSIC; IDENTITY; COMPLEXITY

\footnotetext{
Cornelio Yacaman, Jaime Alejandro. 2015. "El rol del ruido en la conformación de la identidad sonora de un lugar”. AusArt 3 (2): 215-225. DOI: 10.1387/ausart.15962
}

\section{AUSART}




\section{INTRODUCCIÓN}

La confluencia entre música, identidad, espacio y plástica, es el foco de mi investigación. Esta confluencia que expresa la relación entre la identidad del sujeto y su entorno, constituye una identidad territorial gráfico-sonora que viene siendo trabajada en el arte y en la música a través de la historia. Sin embargo, esta confluencia no siempre está libre de dificultades, tanto técnicas como conceptuales, que son el origen de mi doble pregunta de investigación: ¿cómo revelar la identidad de un lugar a través del sonido? y ¿cuáles son los elementos fundamentales de esta identidad del ecosistema que constituyen esta traducción?

Para explorar estas preguntas es necesario comprender cuáles son los elementos que componen la identidad sonora en un ecosistema determinado y cómo esta identidad se manifiesta a través del sonido y de la plástica como una forma gráfico-sonora de identidad. La hipótesis es que existen elementos de identidad sonora que se encuentran en determinados ecosistemas y que responden a la complejidad en los distintos fenómenos que le rodean (geológicos, meteorológicos, sociales, etc.). Entre estos elementos el ruido es uno de los más importantes puesto que forma parte de una experiencia cognoscitiva que es posible analizar e identificar a través de medios tecnológicos y experimentales y desde un marco teórico basado en la noción de complejidad.

A partir del concepto de ecosistema sonoro (desarrollado en mi tesis de doctorado y basado en relación con el concepto de ecosistema, identidad y territorio) el objetivo de este artículo es analizar el papel del ruido en la conformación de la identidad sonora territorial. El análisis será realizado a partir de las teorías de la complejidad y algunos estudios de caso (obra propia; Cusack; Citys and memory, 2015; Carruth, 2013; Polack, 2014) para identificar las relaciones existentes entre territorio, ruido e identidad.

\section{BREVE ESTADO DE LA CUESTIÓN \\ 2.1 Música, identidad, espacio y Sonido}

En diversas culturas y a través de la historia, existe una constante relación entre el ser humano y la naturaleza. Esta relación se establece gracias a 
la percepción del entorno a través de los sentidos en las que se entrelazan sonido, espacio, entorno, identidad y ecosistema y se expresan a través del arte en la confluencia entre música y gráfica.

Algunas referencias en cuanto a las relaciones entre sonido, música y ruido, se encuentran en la obra de John Cage (Rocha, 2013; Cage, 2013). La importancia del silencio y la introducción del ruido en su música, así como las ideas sobre obra abierta y sus performances, son algunas de las aportaciones que hace al Arte Sonoro.

Inspirado por la obra de Cage, Murray Schafer (1969) es sin duda uno de los pioneros en el estudio del ambiente sonoro a través del Paisaje sonoro. Con el fin de analizar el ambiente acústico de la vida cotidiana y entender el fenómeno sonoro y auditivo, surge este concepto como medio para entender la influencia que ejerce en el comportamiento humano, desde una visión interdisciplinaria y un enfoque educativo.

Laranjeira (2014) confirma que los estudios realizados en torno al sonido a partir de 1970 abrieron las posibilidades creativas, y que, actualmente, con el creciente avance tecnológico, estas posibilidades en el ámbito sonoro son cada vez más extensas y variadas. Propone el estudio del sonido desde la semiótica y el concepto de Auralidad como fenómeno perceptivo de la espacialidad, para entender mejor la cualidad de la percepción auditiva, que a diferencia de la visual, ofrece una experiencia mas extensa y compleja del espacio, gracias a sus propiedades cualitativas, significativas y simbólicas.

José Maunel Berenger, también apunta que el fenómeno sonoro y el ruido, forman parte de la significación, como una necesidad arraigada de la naturaleza cultural pero que no puede separarse del entramado biológico. En este sentido, el ruido como hecho comunicativo es cada vez más latente en el panorama actual, principalmente, en contextos urbanos donde la mezcla cultural como fenómeno en crecimiento, plantea complejas contradicciones en cuanto a las actitudes culturales respecto al uso del sonido. Asegura que en los medios de comunicación está la base bio-cultural en la que se articula la sociedad actual.

\subsection{Identidad del Sonido en el territorio de la memoria}

250 Miles Crossing Filadelfia (2014), es un mapa emocional de Google Earth animado con sonido, que traza rutas de senderismo emocionales a través de algunos puntos visitados en Filadelfia. La pareja de artistas holandeses 
Esther Polak e Ivar van Bekkum, crean su propio mapa subjetivo de la ciudad. Bekkum, conectado a un micrófono va grabando sus propios recuerdos y emociones en libre asociación, mientras que Polak, su esposa, provoca en silencio sus pensamientos a través de preguntas escritas a mano en tarjetas, para no interrumpir el monólogo grabado, llevando consigo también un dispositivo GPS para rastrear electrónicamente sus movimientos. Posteriormente recogen respuestas e impresiones para el montaje y realización de una red de voluntarios para hacer lo mismo.

\subsection{IDENTIDAD DE UN LUGAR A TRAVÉS DEL SONIDO}

Sounds from dangerous places (2012) es un libro con CDs, donde Peter Cusack describe la práctica de grabación de campo y el importante papel que juega en la discusión y documentación de los lugares, temas y eventos, dónde escuchar sonidos de todo tipo. Dirigiendo el enfoque de su investigación a través de narrativas en el lugar, muestra lo que se puede aprender de los lugares peligrosos escuchando sus sonidos.

En contacto con lugares difíciles y potencialmente peligrosas, la mayoría áreas con mayor daño ambiental ecológico, Cusack señala que el peligro no es necesariamente para un visitante a corto plazo, pero si para la gente que habita en esos lugares sin opción de poderse desplazar, gracias a la función que ejerce la ubicación en las estructuras de poder geopolíticos. De esta manera, muestra como estos lugares peligrosos pueden ser tanto musicalmente y visualmente atractivos en la dicotomía entre una respuesta estética y el conocimiento del peligro, tratándose de la contaminación, la injusticia social, militar o geopolítica.

\subsection{Música, terRitorio y RUido. InTERVEnCión del ESPACIO SONORO}

Los aborígenes australianos cantan el territorio, a través de los llamados Dreamtimes, que son expresiones en torno a su mitología en la concepción de que, aborígenes y naturaleza forman una unidad. Esas expresiones se manifiestan en el canto y a su vez crean un sistema complejo de códigos gráficos que corresponden a cada zona del lugar, historias, personajes y recorridos.

Las prácticas de los aborígenes australianos me recuerdan los contenidos de la página web Cities and Memory ${ }^{1}$ que busca cartografiar el sonido real e 
imaginario del mundo en una grabación de campo global y obras de arte con sonido que muestran la realidad actual de un lugar, pero a su vez transformándola en una realidad imaginada. Estas son colaboraciones de registro sonoro de campo, a través de un mapa de sonido, acompañada de una reelaboración, transformación e interpretación, imaginando el lugar y el tiempo como otro lugar, manipulando estos sonidos por medio de efectos e instrumentos. Este es un proyecto abierto a las documentaciones de campo, grabadores, artistas sonoros, músicos o cualquier persona interesada en la exploración de sonido en todo el mundo.

\subsection{ECOSistema y CONTAMINACiÓN SONORA}

La película estadounidense Upstream Color de Shane Carruth (2013), es una muestra de las relaciones entre lo humano y lo artificial, en la transformación del ecosistema a causa de la contaminación y los daños producidos por todo lo que se construye. La historia se centra en la vida de dos personajes vinculados inconscientemente a un parásito, un ser con un ciclo de vida que se transmite de la orquídea, al cerdo y después al humano. Este lazo afecta en el comportamiento de los personajes, aumentando la sensibilidad del ultrasonido.

El tema de esta película de ciencia ficción, nos lleva a investigar sobre el concepto de antropoceno y del infrasonido, como fenómenos causados por el impacto que producen las máquinas y la tecnología en el ecosistema, una referencia a la formación de una nueva era geológica que se superpone a las anteriores, que incluye el impacto humano sobre el planeta, incluyendo los aspectos sonoros pues estos afectan gravemente a las especies que se comunican a través de bandas sonoras similares a la longitud de ondas de las máquinas.

\section{IDENTIDADES SONORO-ESPACIALES}

Como hemos visto, existen elementos de identidad sonora que se encuentran en determinados ecosistemas y que responden a la complejidad de los distintos fenómenos que le rodean. El ruido es uno de los elementos más importantes puesto que forma parte de una experiencia cognoscitiva que es posible analizar e identificar. A partir de la doble pregunta de investigación: 
¿cómo revelar la identidad de un lugar a través del sonido? y ¿cuáles son los elementos fundamentales de esta identidad del ecosistema que constituyen esta traducción? el objetivo del artículo es analizar el papel del ruido en la conformación de la identidad sonora territorial (ecosistemas sonoros).

Las teorías de la complejidad pueden ayudarnos a comprender algunos aspectos relacionados con las cuestiones de investigación, pues plantean una necesaria relación entre las distintas disciplinas para explorarlas, en lo referente a las cualidades espaciales y temporales del sonido y el rol del ruido.

Opuesta a la unidimensionalidad del conocimiento y la separación entre realidad objetiva y subjetiva del pensamiento tradicional, el enfoque de la complejidad sugiere que el conocimiento no es algo absoluto y tiene que ver directamente con el sujeto que investiga, así como con los fenómenos que intervienen en ese proceso. Esto es fundamental para comprender la identidad sonora porque todo conocimiento inicia con la percepción sensorial subjetiva del lugar, relativa a cada individuo en relación a su entorno. La apropiación subjetiva es parcial y fluida. Está sometida a parámetros culturales y aprendidos. Esto indica que la 'identidad sonora' de un lugar es fruto de la percepción subjetiva del mismo, filtrada por estos parámetros tanto culturales por parte de quien percibe el ecosistema sonoro como por las propias características de este ecosistema, conformadas a través de múltiples factores, tanto sociales, culturales, biológicos, naturales o artificiales tales como la topografía (con su impacto en la acústica, las actividades humanas y sus ruidos, la naturaleza como generadora de sonidos (viento, mar, lluvia, etc). Todo ello nos permite entender el ruido como uno de estos elementos que contribuyen a la configuración compleja de la identidad sonora de un lugar; una identidad en-proceso, difícil de definir e imposible de reproducir.

El fenómeno de auto-eco-re-organización propuesto por Morin (1994) puede iluminar el rol del ruido en la conformación del identidad sonora territorial:

"La auto-eco-re-organización es una trampa para el azar, para el aléa, para el desorden, para la perturbación, para el ruido, que funciona precisamente porque comporta en su seno azar, desorden, perturbación, ruido integrados en diversas formas de identidad." 
El concepto de auto-eco-re-organización invita a pensar que el ruido obliga a la re-organización de la identidad sonora, el un factor importante que resulta en una 'mutación' (Solana Ruiz, 2905: 77) de la identidad sonora de un lugar gestionada por el azar. En concreto indica para comprender un ecosistema sonoro hay que considerarlo como un conjunto de sistemas, en el cual hay una serie de interacciones e interrelaciones espacio-temporales que se manifiestan en determinado territorio. Estas interacciones escapan muchas veces a nuestro campo perceptivo y, dependiendo tanto de las facultades de cada individuo como de las condiciones externas y de los medios que utiliza, pueden ser traducidas o abstraídas con mayor o menor alcance. En este sentido, cada persona percibe identidades sonoras en un territorio o un recorrido de modo fluido y casi imposible de ser representado. El sujeto inmerso en el medio construye su propia significación de cada lugar a partir del sonido y teniendo al ruido como el elemento que desencadena una mutación del ecosistema sonoro.

Para Dewey (1948), el conocimiento es la experiencia en la que se da un proceso de acontecimientos e historias sucesivas. La experiencia humana refleja el mundo y esa reflexión es una característica intrínseca. La posibilidad de unir distintos lenguajes a través de la video creación, sonido, fotografía e imagen, me permitió descubrir métodos, que aunque ya explorados, pudieran ser desplazados a mi territorio, experiencia y expresión como identidad.

Whitehead (1968) por su parte, propone que el conocimiento se da desde la percepción sensorial en la toma de conciencia de las entidades reveladas por la naturaleza como fuerza creadora y en la cual, entidad o un complejo de entidades, son las cosas que percibimos como parte de una totalidad en el conocimiento de la naturaleza; pero no como una unidad instantánea y absoluta, sino por una serie de relaciones; y en esa totalidad, está el individuo. La percepción de dichas entidades, es relativa a cada individuo respecto a su entorno.

Entendiendo la construcción de los espacios, explicada por Whitehead, y en la congruencia y construcción de un espacio a temporal que correlaciona los espacios momentáneos sucesivos de un sistema dado en el tiempo (hasta ahora no considerados por las teorías absolutas del espacio y el tiempo) y como una abstracción de los hechos naturales, una identidad sonora correspondería a una partícula finita de una serie de acontecimientos, en los cuales existen relaciones de tridimensionalidad espacial, según la teoría alternativa del espacio, ocupando una posición, como cualidad en virtud de los momentos de intersección que lo cubren. 
En este sentido, para la producción de conocimiento de acuerdo al autor, existen tres componentes: el hecho, los factores y las entidades. El hecho, es el término indiferenciado de la toma de consciencia sensorial. Los factores son los términos de esa toma de conciencia y las entidades a diferencia del hecho, son los factores en función de términos del pensamiento. En la naturaleza como complejo de entidades, están sus relaciones y conexiones, tanto naturales como no naturales. Desde esta perspectiva las identidades sonoro-espaciales son partículas de acontecimientos, que contienen características particulares del hecho, de los factores y de las entidades, que se pueden analizar.

Así, estos sonidos que son separados de una parte de la totalidad, es decir, del ecosistema sonoro de donde son extraídos, son partículas finitas o fragmentos de un todo complejo que sigue en mutación después de la grabación. Con estas partículas elaboro samplers y secuencias, haciendo uso de medios electrónicos, para la re-interpretación de estos elementos, como parte de las identidades sonoras de un lugar.

Hemos hecho un breve análisis de algunas referencias principales en relación con el tema. Enfocamos la relación entre música, identidad, espacio y ruido en algunos proyectos, resaltando los rasgos relevantes de esta relación y tomando en consideración todas estas teorías respecto al sujeto como portador de la experiencia cognoscitiva, así como las ideas acerca de la percepción de los distintos elementos o entidades, relativa a cada individuo respecto a su entorno y los factores que le influyen.

\section{ANÁLISIS DE UN CASO DE ESTUDIO}

Como resultado de mis experimentaciones con sonidos, y usando las partículas de identidad sonora previamente seleccionadas y diferenciadas, surge una expresión o una serie de expresiones denominadas identidades sonoro-espaciales.

Este proyecto constituye una serie de piezas musicales con texturas sonoras de un determinado contexto, y aunque el ejercicio no es nada nuevo, teniendo sus referentes en trabajos de música electrónica y sus antecedentes en la música concreta, es un medio que me permite descubrir y desarrollar los principios de una metodología artístico-experimental, en la que se mues- 
tran una serie de características particulares de un lugar, tiempo y espacio, a través de la utilización de elementos sonoros seleccionados (como bullicios de ciudad, ruido de transporte, etc.) bajo unos criterios de exploración que finalmente se traducen en la propia re-interpretación.

En la segunda fase del proceso, establezco relaciones con la gráfica en el uso de fotografía, dibujo y video, buscando una interacción con la composición musical pero no necesariamente relacionadas de forma directa. Son partículas presentes en el espacio, tomadas de distintos momentos y lugares, en las que se establecen unas relaciones a partir de lo que me sugiere el ritmo, la frecuencia del sonido y el qué de esos sonidos por su contenido, es decir, lo que estos sonidos revelan. Esta interacción entre las dimensiones del sonido y lo visual en su conjunción, dan como resultado una serie de video-creaciones y audios por separado, unidos por relaciones sonoro-espaciales, partiendo del hecho musical y no necesariamente para una lectura lineal.

El total de la obra comprende cuatro video-creaciones y seis pistas en formato wav y mp3 y en proceso para la creación de un disco de artista (CD) y una plataforma web para su reproducción, basándose en las aplicaciones de Google Maps, así como la posibilidad de materializar esas identidades a través de la impresión 3D, impresión digital, medios gráficos u otros.

En Identidad sonoro espacial 3, establezco la relación entre el ruido, la composición musical y el espacio temporal del entorno de una ciudad, resaltando la identidad de un sonido característico y en interacción con secuencias de imágenes de graffiti, fachadas deterioradas etc.

De esta forma, la complejidad del sonido como fenómeno natural en sus relaciones de espacio, posibilitan la creación artística contemporánea y la experimentación del ruido utilizando medios tecnológicos para su captura, manipulación y transformación.

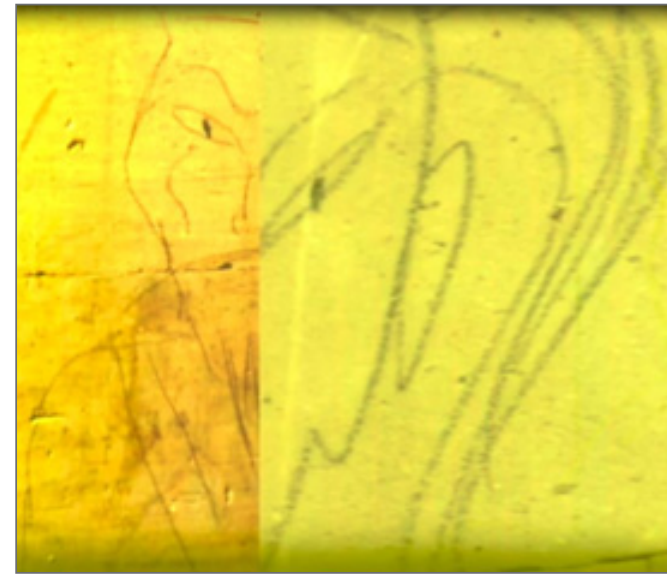

Fig.1:Identidad3(2013-2015), Jaime Yacaman Video creación (02:41) Duración total 04:23 https://vimeo. com/146946639 
Para concluir y desde la perspectiva de la complejidad, podemos entender la identidad como lo nombrado e identificado bajo categorías subjetivas que se basan en rasgos determinados, ya sean cualidades físicas, territoriales, culturales, etc. Al nombrarlas e identificarlas se le atribuyen rasgos característicos en un proceso para el conocimiento.

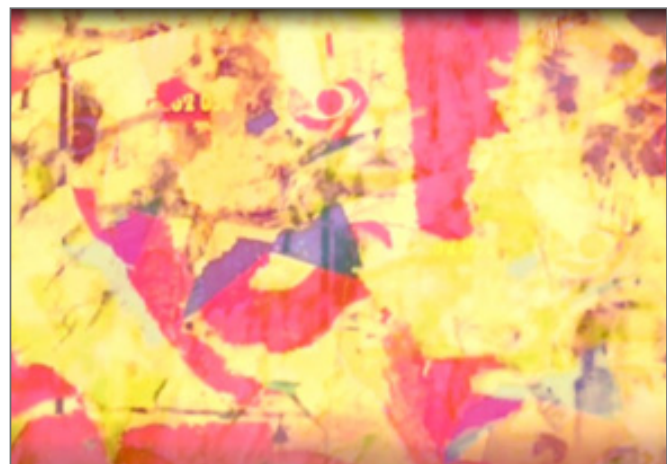

Fig.2: Identidad 3 (2013-2015), Jaime Yacaman Video creación (02:59) Duración total 04:23 https://vimeo. $\mathrm{com} / 146946639$
El análisis de los fenómenos como entidades y sistemas complejos, permite entender el papel del ruido como parte conformadora de la identidad de un lugar, desde sus relaciones con otras identidades, sus expresiones, así como los factores que intervienen. Como fenómeno físico y expresivo nos ofrece también múltiples lecturas y reflexiones, desde, cómo nos afecta el ruido en un lugar y un tiempo determinado, el papel que desempeñamos en la producción y escucha del sonido, y las aportaciones que el arte puede ofrecer en todos estos planteamientos para solucionar y mejorar la calidad de nuestra entorno.

\section{Referencias}

Berenguer Alarcón, Josep Manuel. 2005. “Ruidos y sonidos: Mundos y gentes”. En Espacios sonoros, tecnopolítica y vida cotidiana: Aproximaciones a una antropología, Andrés Antenbi et al., ed. con motivo del Festival Zeppelin. Barcelona: Sonora Orquestra del Caos. http://www.antropologia.cat/files/DOSSIER\%20ESPACIOS\%20SONOROS.pdf

Cage, John. 2013. "About the John Cage Trust”. johncage.org. Acceso 4 jun. 2014 http://johncage.org/about.html

Carruth, Shane. 2013. Upstream Color. Director and writer, Shane Carruth. 01:36:00. http:// www.imdb.com/title/tt2084989/

Chatwin, Bruce (1987) 2000. Los trazos de la canción. Traducción de Eduardo Goligorsky. Barcelona : Círculo de Lectores

Cornelio Yacaman, Jaime. 2015. "Identidades sonoroespaciales: Identidad 3", Vídeo de Vimeo, 4:22. Acceso may. 2015 https://vimeo.com/146946639

Crimmins, Peter. 2014. "Guided by impression and free association, Dutch artists chart emotional map of Philly". News Work, May 28. Acceso 19 jul. 2015, http://www.newsworks.org/ 
index.php/local/item/68431guidedbyimpressionandfreeassociationdutchartistschartemotionalmapofphiladelphia?linktype $=\mathrm{hp}$ topstory

Cusack, Peter. 2012. “Sounds from dangerous places”. Sitio web. Acceso 6 jun. 2015. http:// sounds-from-dangerous-places.org/

Da Vinci, Leonardo. (1513) 2013. Tratado de pintura. Traducción, prólogo y notas de David García López. Madrid: Alianza

Dewey, John. (1925) 1948 La experiencia y la naturaleza. Prólogo y versión española por José Gaos. México DF: Fondo de Cultura Económica

Kandinskiï, Vasiliï Vasil'evich. (1911) 1996. De lo espiritual en el arte. Traducción de Genoveva Dieterich. Barcelona: Paidós

- (1926) 1996. Punto y línea sobre el plano: Contribución al análisis de los elementos pictóricos. Traducción Roberto Echavarren. Barcelona: Paidós

Laranjería, José dos Santos. 2014. "Tránsitos sonoros: El paisaje sonoro a partir de las tramas de la sincronicidad en el arte contemporáneo". Tesis Univ. Barcelona, http://www.tdx.cat/ handle/10803/285405

Morin, Edgar. 1974. El paradigma perdido: Ensayo de bioantropología. Traducción de Domènec Bergadà. Barcelona: Kairós

- 1994. Introducción al pensamiento complejo. Ed. española a cargo de Marcelo Pakman. Barcelona: Gedisa

Schafer, R. Murray. 1965. El compositor en el aula. Traducción de Beatriz Spitta. Buenos Aires: Ricordi

- 1969. El nuevo paisaje sonoro: Un manual para el maestro de música moderno. Traducción de Juan Schultis. Buenos Aires: Ricordi

Solana Ruiz, José Luis, coord. (2005) Con Edgar Morín, por un pensamiento complejo: Implicaciones interdisciplinares. Madrid: Akal

Whitehead, Alfred North. (1920) 1968 El concepto de naturaleza. Versión española de Jesús Díaz. Madrid: Gredos

\section{Notas}

${ }^{1}$ http://citiesandmemory.com 